\title{
Can Your Spouse Accurately Report Your Activities? An Examination of Proxy Reporting
}

Tim Triplett

Keywords: survey practice

DOI: $10.29115 /$ SP-2010-0002

\section{Survey Practice}

Vol. 3, Issue 1, 2010

Can Your Spouse Accurately Report Your Activities? An Examination of Proxy

Reporting

The 2008 Survey of Public Participation in the Arts (SPPA) is sponsored by the National Endowment for the Arts and was conducted as a supplement to the May 2008 Current Population Survey (CPS). A big challenge in being a supplement to the CPS is that respondent selection procedures for the SPPA supplement differ from the CPS procedures. The CPS is administered to any person 16 or older who is able to report employment information on all persons 16 years or older in the household. While the SPPA collects information on all adults 18 or older, it is felt that many of the questions on the survey require self reports rather than proxy reports. In 2002, the Census Bureau interviewers attempted to complete the SPPA supplement with all persons 18 or older, but after 4 call attempts they accepted proxy reports. To make the SPPA a better fit for the CPS protocol, rather than attempt to interview all adults in the household, the 2008 SPPA accepted proxy responses for spouses or partners (for many of the questions). This change in design makes it much easier to measure the impact of proxy reports, given that they were collected by design rather than out of necessity. This research explores the extent to which proxy reporting may have resulted in over or under reporting participation.

\section{OVERVIEW OF PROXY REPORTING}

Why should you consider accepting a proxy response? In most situations you would most likely want to question people directly, however, many surveys allow a knowledgeable respondent to answer on behalf of others. There are three main reasons why surveys accept proxy responses. First, there is proxy out of necessity because the individuals that you would like to interview are unable to respond on their own behalf, because they are either too young or too old to respond or cannot respond due to a physical or mental condition. Some surveys will exclude these individuals, while other surveys will accept a 
proxy response because excluding them would lead to bias estimates. Second, there is proxy to increase the efficiency of a survey. This occurs when you accept proxy responses for people capable of providing their own information in order to save money and time. If information about others or everyone in a household is collected from one person, it is possible to obtain a larger sample size with just one contact, thereby improving response rates and reducing costs. Third, there is proxy to improve the quality of the data for studies in which it is believed that proxy information would be as good as or perhaps even better than the information you would obtain from a direct interview. A very common situation of proxy by design is getting information about a child from a parent. Other examples include getting financial information on people from the family member who pays the bills or keeps the checkbook, and getting eating habits from the person who prepares most of the meals.

There are many major surveys that rely on proxy responses, including the Current Population Survey (CPS), which uses one respondent to collect labor force data on all the members of a household. Since proxy reporting is widely used, the accuracy of proxy reporting has been well studied. (Tourangeau, Ri ps, and Rasinski 2000) We do know that in general proxy responses have the potential to be less accurate than information obtained directly from sampled respondents. However, less is known about the degree of proxy reporting inaccuracies and whether particular types of proxy respondents (spouses, parents, or others) are more likely to provide accurate information about the sampled person. The 2008 SPPA survey design purposely allowed many of the questions to be proxy reported by a spouse or partner who themselves were randomly selected. This design makes it possible to learn more about the capability of spouses or partners to serve as proxy respondents for their partners.

\section{SPPA SURVEY DESIGN}

The 2008 SPPA was conducted as a supplement to the May 2008 Current Population Survey (CPS). Approximately 60,000 households are eligible for the CPS. Sample households are selected by a multistage stratified statistical sampling scheme. The SPPA supplement was administered in households in their 4th and 8th months of their CPS commitment (often referred to as the "outgoing rotation groups"). This led to SPPA interviews being conducted in 10,089 households. Data on 18,444 adults were obtained from interviews conducted in these 10,089 households.

The CPS is administered to any person 16 or older who is able to report household employment information while the SPPA collects information only on adults 18 or older. In the event that the CPS respondent was under 18 years of age, the first adult respondent was chosen at random from amongst all adults 18 or older. Otherwise, the first SPPA interview in the household was conducted with the CPS respondent or their spouse/partner (chosen at random) if they had a partner. In addition, a second supplemental interview 
was conducted in households that had adults in addition to the CPS respondent and their spouse or partner. The second interview was done with a randomly selected adult from among the remaining non-interviewed adults.

The nature of many SPPA questions requires that the survey be based on direct self reports rather than proxy reports. After doing some extensive testing of spouse/partner proxy reporting, it was decided that for the 2008 SPPA respondents who had a spouse or partner would also be asked to report on their core participation activities as well as their partner's leisure activities (module $\mathrm{C}$ of the questionnaire). Of the overall 18,444 SPPA adult respondents, 5,926 or just over 30\% were obtained through spouse/partner reports.

Because the SPPA questions are asked after the Monthly CPS questions, the SPPA response rate is lower than the overall CPS response rate. However, the response rate for the 2008 SPPA was $81.6 \%$, calculated by dividing the 18,444 adult interviews by the 22,603 who were selected to complete the supplement.

Item nonresponse (questions that people refused or did not know the answer to) is relatively low, averaging $<1$ percent for the main SPPA core participation questions and just above 1 percent across all SPPA questions. Interestingly, the percentage of don't know or refused responses is slightly lower for the spouse/ partner proxy reports than the overall self-reported responses. However, this difference does not hold up when you control for the fact that proxy respondents all have a spouse/partner, because item nonresponse is higher amongst non-married respondents. Roughly the same percentage of item nonresponse could be attributed to both men and women, though women were more likely to choose the "don't know" or "refuse" option (1.05\% average nonresponse) than their spouse/partner did when reporting about them $(0.9 \%)$.

\section{COMPARISON OF PROXY VERSUS SELF-REPORTED DATA}

Overall participation information from the spouse or partner may have led to slightly lower estimates for a few participation activities. For most variables the spouse/partner proxy reports yielded slightly lower participation rates, but usually too small to have any impact on the overall participation estimates. In fact, for the most part estimates from spouse/partner proxy reports were remarkably similar to self-reported estimates. However, there were a few SPPA estimates that may have been slightly higher had there been only self-reported data (reading, visiting art museums, exercise). While there were some gender differences, there were no differences found when comparing spouse/partner proxy reporting versus self report by age, race, and region.

Table 1 shows the difference between the core participation estimates using all respondents versus excluding the spouse/partner proxy reported data. Similarly, Table 2 shows differences in the estimates from all respondents and those estimates that exclude the spouse/partner proxy reports for other leisure activities. These two tables also show these differences separately for men versus 
women. The estimates for all respondents and the estimates that exclude spouse/partner reports are both weighted so that they are representative of the adult non-institutionalized U.S. population. 
Table 1 Comparison of Core Arts Participation Activities.

\begin{tabular}{|c|c|c|c|c|c|c|}
\hline $\begin{array}{l}\text { Attended (last } 12 \\
\text { months) }\end{array}$ & $\begin{array}{l}\text { All } \\
\text { Respondents }\end{array}$ & $\begin{array}{l}\text { Excluding Partner } \\
\text { Proxy }\end{array}$ & $\begin{array}{l}\text { All Male } \\
\text { Respondents }\end{array}$ & $\begin{array}{l}\text { Males Excluding Partner } \\
\text { Proxy }\end{array}$ & $\begin{array}{l}\text { All Female } \\
\text { Respondents }\end{array}$ & $\begin{array}{l}\text { Females Excluding Partner } \\
\text { Proxy }\end{array}$ \\
\hline Jazz Performance & $7.8 \%$ & $7.9 \%$ & $7.7 \%$ & $8.1 \%$ & $7.9 \%$ & $7.7 \%$ \\
\hline Latin Music & $4.9 \%$ & $5.0 \%$ & $4.8 \%$ & $5.0 \%$ & $4.9 \%$ & $5.1 \%$ \\
\hline Classical Music & $9.3 \%$ & $9.3 \%$ & $8.5 \%$ & $9.1 \% * *$ & $10.0 \%$ & $9.6 \%^{* * *}$ \\
\hline Opera Performance & $2.1 \%$ & $2.0 \%$ & $1.8 \%$ & $1.9 \%$ & $2.4 \%$ & $2.2 \%^{* * *}$ \\
\hline Musical Play & $16.7 \%$ & $16.9 \%$ & $14.4 \%$ & $14.4 \%$ & $18.9 \%$ & $19.2 \%$ \\
\hline Non-Musical Play & $9.4 \%$ & $9.5 \%$ & $8.2 \%$ & $7.8 \% * *$ & $10.6 \%$ & $11 \%^{* * *}$ \\
\hline Ballet & $2.9 \%$ & $3.0 \%$ & $2.2 \%$ & $2.3 \%$ & $3.6 \%$ & $3.6 \%$ \\
\hline Other Dance & $5.2 \%$ & $5.3 \%$ & $4.4 \%$ & $4.5 \%$ & $5.9 \%$ & $6.1 \%$ \\
\hline \multicolumn{7}{|l|}{ Visited } \\
\hline Art Museum & $22.7 \%$ & $23.3 \%^{*}$ & $21.4 \%$ & $21.6 \%$ & $24.0 \%$ & $24.9 \%^{* * *}$ \\
\hline Art/Craft Fair & $24.5 \%$ & $24.8 \%$ & $20.5 \%$ & $20.2 \%$ & $28.3 \%$ & $29.1 \%^{* * *}$ \\
\hline Outdoor Festival & $20.8 \%$ & $20.9 \%$ & $20.6 \%$ & $20.9 \%$ & $20.9 \%$ & $21.0 \%$ \\
\hline Historic Park & $24.9 \%$ & $25.2 \%$ & $24.4 \%$ & $23.8 \%^{* *}$ & $25.4 \%$ & $26.4 \%^{* * *}$ \\
\hline \multicolumn{7}{|l|}{ Read } \\
\hline Books & $54.3 \%$ & $55.6 \%^{*}$ & $46.3 \%$ & $47.8 \%^{* *}$ & $61.7 \%$ & $62.8 \% * * *$ \\
\hline Novels & $47.0 \%$ & $48.3 \%^{*}$ & $38.4 \%$ & $40 \%^{* *}$ & $54.9 \%$ & $56.1 \%^{* * *}$ \\
\hline Poetry & $8.3 \%$ & $9.1 \%^{*}$ & $6.6 \%$ & $7.1 \%^{* *}$ & $9.8 \%$ & $11 \%^{* * *}$ \\
\hline Plays & $2.6 \%$ & $2.8 \%^{*}$ & $1.9 \%$ & $1.9 \%$ & $3.2 \%$ & $3.6 \%^{* * *}$ \\
\hline
\end{tabular}


Table 2 Comparison of Other Leisure Activities.

\begin{tabular}{|c|c|c|c|c|c|c|}
\hline $\begin{array}{l}\text { Attended (last } 12 \\
\text { months) }\end{array}$ & $\begin{array}{l}\text { All } \\
\text { Respondents }\end{array}$ & $\begin{array}{l}\text { Excluding Partner } \\
\text { Proxy }\end{array}$ & $\begin{array}{l}\text { All Male } \\
\text { Respondents }\end{array}$ & $\begin{array}{l}\text { Males Excluding Partner } \\
\text { Proxy }\end{array}$ & $\begin{array}{l}\text { All Female } \\
\text { Respondents }\end{array}$ & $\begin{array}{l}\text { Females Excluding Partner } \\
\text { Proxy }\end{array}$ \\
\hline Movies (at theater) & $53.3 \%$ & $53.3 \%$ & $52.7 \%$ & $53.0 \%$ & $54.0 \%$ & $53.6 \%$ \\
\hline $\begin{array}{l}\text { School Arts } \\
\text { Performance }\end{array}$ & $23.7 \%$ & $23.6 \%$ & $20.4 \%$ & $19.2 \%^{* *}$ & $26.7 \%$ & $27.6 \%^{* * *}$ \\
\hline $\begin{array}{l}\text { Church Arts } \\
\text { Performance }\end{array}$ & $19.1 \%$ & $19.0 \%$ & $17.1 \%$ & $16.6 \%$ & $21.0 \%$ & $21.3 \%$ \\
\hline Sports Event & $30.6 \%$ & $30.7 \%$ & $34.9 \%$ & $35.8 \% * *$ & $26.6 \%$ & $26 \%{ }^{* * *}$ \\
\hline \multicolumn{7}{|l|}{ Did you (last 12 months) } \\
\hline Exercise & $52.9 \%$ & $53.6 \% *$ & $52.1 \%$ & $52.6 \%$ & $53.6 \%$ & $54.6 \%^{* * *}$ \\
\hline Participate in Sports & $26.3 \%$ & $26.7 \%$ & $33.2 \%$ & $33.7 \%$ & $20.0 \%$ & $20.1 \%$ \\
\hline Camp, hike, Canoe ... & $28.2 \%$ & $28.2 \%$ & $31.1 \%$ & $30.3 \%^{* *}$ & $25.4 \%$ & $26.2 \% * * *$ \\
\hline Gardening & $41.6 \%$ & $41.6 \%$ & $33.6 \%$ & $33.3 \%$ & $48.9 \%$ & $49.3 \%$ \\
\hline Pottery, Ceramics ... & $6.0 \%$ & $5.8 \%$ & $4.5 \%$ & $4.2 \%$ & $7.4 \%$ & $7.3 \%$ \\
\hline Weaving, sewing ... & $13.1 \%$ & $13.4 \%$ & $2.3 \%$ & $2.3 \%$ & $23.2 \%$ & $23.8 \%^{* * *}$ \\
\hline Photography, Movies ... & $14.7 \%$ & $14.9 \%$ & $13.3 \%$ & $12.4 \%^{* *}$ & $16.1 \%$ & $17.3 \%^{* * *}$ \\
\hline Painting, Sculpture ... & $9.0 \%$ & $9.2 \%$ & $7.1 \%$ & $7.2 \%$ & $10.7 \%$ & $11.1 \%$ \\
\hline Creative Writing & $6.9 \%$ & $7.0 \%$ & $6.2 \%$ & $6.2 \%$ & $7.5 \%$ & $7.7 \%$ \\
\hline Play Musical Instrument & $12.6 \%$ & $13.3 \%^{*}$ & $14.5 \%$ & $15.3 \%^{* *}$ & $11.0 \%$ & $11.5 \%^{* * *}$ \\
\hline Sing in a Choral, Choir... & $5.2 \%$ & $5.3 \%$ & $3.9 \%$ & $4.1 \%$ & $6.3 \%$ & $6.5 \%$ \\
\hline Dance Ballet or other... & $2.1 \%$ & $2.2 \%$ & $1.4 \%$ & $1.5 \%$ & $2.8 \%$ & $2.9 \%$ \\
\hline \multicolumn{7}{|l|}{ Other Activities } \\
\hline Community Activities & $27.8 \%$ & $28.3 \% *$ & $26.2 \%$ & $26.3 \%$ & $29.3 \%$ & $30.1 \%^{* * *}$ \\
\hline $\begin{array}{l}\text { Volunteer/Charity } \\
\text { Work }\end{array}$ & $32.0 \%$ & $32.2 \%$ & $28.9 \%$ & $29.2 \%$ & $34.9 \%$ & $35.1 \%$ \\
\hline $\begin{array}{l}\text { Vote Presidential } \\
\text { Election }\end{array}$ & $63.1 \%$ & $63.3 \%$ & $61.5 \%$ & $62.0 \%$ & $64.6 \%$ & $64.5 \%$ \\
\hline \multicolumn{7}{|l|}{ Watch Television } \\
\hline Hours per day & 2.99 & 2.97 & 2.91 & 2.91 & 3.06 & 3.03 \\
\hline
\end{tabular}

${ }^{*}$ Difference from all respondents were significant ( $95 \%$ confidence interval). 
Can Your Spouse Accurately Report Your Activities? An Examination of Proxy Reporting

**Differences from all male respondents were significant ( $95 \%$ confidence interval).

${ }^{* * *}$ Differences from all female respondents were significant ( $95 \%$ confidence interval) 


\section{KEY FINDINGS}

- The reporting of arts and other leisure activities by Spouse/Partners worked well and the small differences were more than offset by the benefit of having a much larger sample size.

- A few participation estimates were lower than they would have been had the survey not included spouse/partner proxy reporting.

- When estimates differed, we didn't know what the correct answer was, so:

- In some cases self-reported estimates may be better because people may not be as aware of their partner's activities.

- In some cases proxy reports may be better because there is less potential of over reporting socially desirable activities.

- More significant differences were found when looking just at female estimates that excluded spouse/partner reports. This could be attributed to one or a combination of the following reasons:

- Men are less reliable proxy reporters.

- Men and women tend to define the activities differently.

- Women tend to over report certain types of activities. 


\section{REFERENCES}

Tourangeau, R., L.J. Rips, and K. Rasinski. 2000. The Psychology of Survey Responses. New York: Cambridge University Press. 